\title{
Aktuelle lebensmittelrechtliche Fragestellungen (u. a. BfR Stellungnahme zur Bewertung von Histamin in Lebensmitteln)/Verschiedenes
}

(c) Bundesamt für Verbraucherschutz und Lebensmittelsicherheit (BVL) 2011

Folgende Themen wurden behandelt:

1. Wie ist eine Bratwurst mit einem Zusatz von kollagenen Abbauprodukten (z. B. Gelatine) zu beurteilen?

Ist das Verkehrsverbot nach § 4 Fleisch-Verordnung noch durchsetzbar?

2. Kennzeichnung von Käse und Käsezubereitungen mit einem Gehalt an F. i. Tr. $>32,5 \%$ mit der Angabe „leicht“.
Was ist ein „vergleichbares Produkt“ gemäß dem Anhang der VO (EG) 1924/2006?

3. Sterilmilch: Kennzeichnung der Wärmebehandlung 